\title{
Think-Pair-Share as a Springboard for Study Buddies in a Virtual Environment
}

Excelsior: Leadership in Teaching and Learning 2021, Vol. 14(1), 51-60

(C) The Author 2021 CC-BY 4.0 International Reprints and permissions: surface.syr.edu/excelsior https://doi.org/10.14305/in.

19440413.2021.14.1.04 nyacte.org

\section{Philip J. Sembert II ${ }^{1}$, Paul J. Vermette ${ }^{1}$, Frank Lyman ${ }^{2}$, Mary Ellen Bardsley ${ }^{1}$, and Carolyn Snell ${ }^{1}$}

\begin{abstract}
Many powerful teaching techniques have not yet fully transitioned from face-to-face use to the new remote instructional paradigm forced on teacher educators and teacher candidates during the pandemic. Experiences by candidates and by instructors in this new environment need to be compiled and shared as we head forward into structures and situations. This article describes how one such technique, Think-Pair-Share (Lyman, 1981) inspired assigning Study Buddies in a co-taught graduate level teacher education course, Managing Culturally Responsive Classrooms, in the summer of 2020. Two teacher candidates, two professors and Dr. Frank Lyman, offer insight and suggestions about this practice, its possibilities and its limitations as the course moved from a traditional implementation to a virtual setting.
\end{abstract}

\section{Keywords}

Remote instruction, setting, teaching strategies, think-pair-share, graduate courses

In May 2020, the two professor authors began planning their summer course, Managing Culturally Responsive Classrooms. Administration moved all summer courses online and the professors discussed how to translate various face-to-face teaching strategies into a synchronous, co-taught course with thirty plus students and two instructors. Their conversations focused on what worked well in previous cotaught versions of this course and the capabilities of the Learning Management System (in this case Canvas) and the instructors.

\footnotetext{
${ }^{1}$ Niagara University

${ }^{2}$ University of Maryland College Park

Corresponding Author:

Philip J. Sembert II, 5888 Walmore Rd. Sanborn, NY 14132

Email: philsembert@icloud.com
} 
To move this course online the instructors began by outlining the course readings and the class activities they wanted to use. This helped the instructors to determine which activities might work online and helped them think through how to implement the strategies. One teaching and learning strategy both instructors wanted to use was Think-Pair-Share. First proposed by Frank Lyman (1981), Think -Pair-Share (TPS) uses collaboration as students work together to solve a problem or answer a question. An established teaching strategy, many authors describe how to use TPS (Barkley et al., 2014; Mills, 1990; Simon, N.D.) and research supports the efficacy of TPS across several variables (Cortright et al., 2005; Nik Azlina, 2010; Sugiarto \& Sumarsano, 2014). This article describes the instructors' use of study buddies in an online course. Two students in the course provide their perspective on how the modified TSP, study buddies, engaged them in and out of the course. Finally, Dr. Frank Lyman, creator of Think-Pair-Share, offers his observation.

\section{The Professor Perspective}

Dr. Vermette and Dr. Bardsley co-taught Managing Culturally Responsive Classrooms in a face- to-face setting to graduate teacher candidates in the summer of 2019. We planned and used many effective interactive learning experiences and implemented various forms of Cooperative Learning, including Think-Pair-Share during the course. We are now trusted colleagues and became friends because we worked together, shared ideas, respected each other and have diverse insights, backgrounds and aspirations. This is important to note because in our summer 2020 course, we were modeling professional collaboration for 36 future educators and quite often positive relationships are seen as necessary inputs for cooperation to work. We knew that these relationships should be seen as outputsthe results of our interactions. We wanted a similar experience to be possible for our candidates.

\section{The Instructors: Why We Used TPS as a Fundamental Course Structure}

A host of concepts guided our decision-making regarding the course design. Key amongst them was the constructivist notion of learners creating their own understandings. We saw that candidates needed to deeply process ideas before, during and after a class session. We used individual open-ended reflections for post-class interpretations and used take-home projects (built on readings) as entry tickets. Our candidates were enticed to think and make sense of ideas before class and after the experience. Based on student feedback, assessments, and self- reflections, we felt our 2019 course met these goals.

Moving the course virtually, we knew we wanted to incorporate this same framework. In late spring, as we began planning the 3-hour synchronous version of the course, we discussed what we felt were the important elements of the course delivery. Having candidates listen to us talking for three hours was not feasible. In our minds, group work, Think-Pair-Share, reflection, and guest speakers needed to be included because we were trying to build community, entice conversation, promote collaboration, and spark analysis, and facilitate transfer of learning.

However, using the remote technology is frequently problematic for online instructors during instruction. While breakout rooms allow some team discussion, the technology is often unreliable, and class becomes a very uneven experience across all members. While we still utilized the breakout rooms as ( 4 or 5 person) teamed cooperative learning opportunities, we opted to stress the paired structure offered by Frank Lyman's Think-Pair-Share (1981). We knew this procedure well and one instructor 
(Dr. Vermette) has called it the most "powerful technique available." A host of research studies by Don Dansereau (and colleagues) of Texas Christian University between 1985 and 1999 provided strong evidence of its power in college level courses.

Years ago, Dansereau led several studies that created college-level student pairs that talked to each other, helped each other, "taught" each other, and supported each other. These paired engagements were not formally aligned with Lyman's TPS but were analogous. Vermette (1998) labelled the pair engagements "Dansereau's Dyads" and saw them as a member of a set of more formal cooperative structures like those of Johnson and Johnson (1989) and Slavin (1983).

\section{The Structure and Use of TPS During the Course}

After determining that we wanted to use TPS during this course, we needed to figure out the mechanics for implementation. We typically have candidates complete an "All About Me" survey the first day of class and the gathered information influences future groupings. We changed the timing of this survey slightly and we did a pre-course survey to gain information about the students. We assumed the graduate students would have access to phones and thought calling, messaging, or texting might work for TPS. This particular teacher education program draws American and Canadian candidates. Knowing this, we added a question regarding international phone access to the All About Me survey. The question, "We want to have conversations during EDU 530 class time. Do you have the ability to text during our class time? To someone on the other side of the border?"provided us information about the ability to communicate internationally and whether students were using their phones to view the online course.

We emailed an introduction letter to candidates registered in the course a month before our course started. The candidates in this program are in a cohort and had started their first summer courses. This allowed us access to stable class rosters far ahead of our course starting. This may not be possible in all situations. We assigned the All About Me survey as their first course homework assignment, realizing that candidates could choose not to do anything for us until our course started. Eighty-five percent of the candidates submitted their surveys by the date we requested. The others responded to a follow up email from one of us.

We knew we would be emphasizing the use of collaborative groups in our course. Throughout the course, we stress the need for our future teachers to be purposeful in constructing groups based on best practices (Gonzales et al., 2021; Vermette, 1997). We want our students to meet and work with a variety of people throughout our course and their graduate program.

The information from the All About Me survey allowed us to create purposefully diverse pairs. When possible, the pairs included a male and female, one Canadian and one American, and one candidate seeking elementary certification and one candidate seeking secondary certification. There were fifteen pairs and two trios. Once the pairs were created, we sent the entire class an email introducing the study buddy concept. An email was sent to each pair or trio requesting that they decide on a way to communicate during class and that they be ready to communicate during our first class meeting. In this email, we suggested several ways (e.g., apps, texting) study buddies could communicate but left the choice up to the pairs. Both emails reminded candidates that this was a professional relationship and we needed to respect professional information (e.g., contact information) and conduct ourselves as professionals. We encouraged students to seek out an instructor if there were any issues. Neither instructor was contacted regarding any study buddy issues throughout the semester. 
The first class opened with an explanation of TPS and a discussion about its use. We introduced the term "study buddies." Study buddies were permanent pairings, assigned by the instructor that would engage in TPS, and other conversations, throughout the course. The term, study buddy, stuck before we conflated that word with Think-Pair-Share again.

One of the first activities during our first class involved "talking" with their study buddy (more on this below). Each week we planned at least one activity period where candidates interacted with their study buddy. These activities used TPS as retrieval of course material and connections before an individual assignment and as a reflection, often as an entrance ticket, after completing and submitting an assignment. We moved between having study buddies post a response into the conference platform chat box and asking candidates to share information about the process or product of their study buddy conversations with the entire class.

In these frequent, brief conversations during class, our candidates had:

1. An outlet to gripe about life;

2. a chance to talk without the intrusion of the teachers;

3. the experience of practicing the dispositions of good professionals, this became the Habits of Mind (Costa and Kallick, 2014);

4. the ability to safely ask questions or seek clarifications that they might not unveil in a larger group;

5. the structure to build a stabilizing sense of community with at least one other "stranger";

6. an opportunity to foreshadow the use of "study buddies," a strategy described in the first text we read (Ladson-Billings, 2009);

7. plenty of chances to receive feedback for their intuitive or developing theories and to feel encouragement to "think out loud";

8. a chance to develop an empathetic sense of another person's life, perspective, sense of humor, and reaction to school (and world) events;

9. and, a chance to "own" the technological processes that they needed.

The study buddies did all of these things and more. What began as trying to use a tried teaching strategy, TPS, online to engage students and support their learning, evolved into a pipeline for building classroom community, professional relationships, and into friendships that continued outside of class and after the course ended.

Since this article describes teaching practice rather than a research study, it is important to have students' perspectives. Perspectives from two graduate candidates, and first authors of this paper, follow. Following the students' perspectives, the instructors provide their insights. It is important to note that Philip J. Sembert II and Carolyn Snell were not paired as study buddies. Their individual questions regarding TPS caused one of the instructors who knows Dr. Lyman to introduce Dr. Lyman and the two students via email. The two students engaged in several email exchanges with Dr. Lyman.

\section{Philip J. Sembert II: Teacher Candidate Perspective}

Before my time at Niagara University, I do not recall a time that "Think-Pair-Share" was utilized by my educators. It was during my third and fourth year as an undergraduate at Niagara University that I experienced firsthand the power of this teaching tool. Dr. Pollard, a professor of English, often paired us with a partner, or into small groups to accomplish difficult assignments. It was highly effective, in fact, I 
recall more from those respective courses than any other courses throughout my academic career. There are a few reasons for this, perhaps none more powerful than being responsible for your own learning, but also your partner's learning, and vice-versa. It is important to note that during my time in undergrad, the world was not living and battling through the struggles of a global pandemic, however, the implementation of this powerful and expandable tool is equally as effective in the new virtual classroom.

At face value, it might seem difficult to utilize Dr. Frank Lyman's teaching strategy "Think- Pair Share" in the new virtual settings. However, through experience in my current graduate teacher education program with Dr. Bardsley, and Dr. Vermette, which is done synchronously online via Zoom and Canvas, "Think Pair-Share" has proved to be the versatile teaching strategy that it is in the traditional classroom setting. I thoroughly enjoyed how Dr. Bardsley and Dr. Vermette utilized the idea of "study buddies" to pair students off with peers. During class, we were allotted time to think and then talk with our study buddy to share thoughts. In class, Dr. Bardsley and Dr. Vermette would explicitly tell us that our study buddy time started and to contact each other, may it be a phone call, text messaging, or other communication app. My buddy and I often continued our messaging throughout class to expand on ideas, or just as an outlet to talk about assignments or concepts. Interestingly, the social interaction continued well beyond the classroom. We checked in on one another, asked for advice, and more importantly - built a meaningful and positive professional relationship. We are not alone in this experience, in fact, many other classmates who went through the program experienced the same outcome.

Our professional relationship developed quickly. This is because of an in-class assignment completed day one with our study buddies. During that assignment, we worked together to complete a Venn diagram to find as many commonalities as possible that brought us together. From coffee to dogs to chocolate and food, we realized that we had much in common. This foundational assignment would prove to be incredibly important as our professional relationship flourished and we worked together often throughout the semester. Our professional relationship and lines of communication continue to this day.

One of the most important factors in the virtual Think-Pair-Share format is that our ideas are different, and we learn from one another. If I did not get something, the odds that my partner did were relatively high, and if neither of us understood we encouraged each other to speak up so that we could clarify everything with our instructors. This is valuable because sometimes students have a fear of asking questions, a study buddy helps prevent such fears. It eliminates the awkward feeling of being the only one not to understand a concept. This encouragement brings about another benefit of the Think-PairShare approach in the virtual environment-motivation.

It is my experience that Think-Pair-Share increases motivation to do work and to do work well. You feel responsible not just for your own learning, but also for what you bring to the table to teach your partner and your partner you. This means that we spent much more time focusing with great attention to detail to the course readings and assignments. The private conversations helped us bring content to life. My study buddy would find an idea, I would find another idea, and together we made connections, found commonalities, and constructed a new and deeper understanding of concepts. This helped us feel valued by each other, a social benefit that should not be lost by educators. Overall, the social involvement increased our individual engagement. In a class of $35+$ teacher education candidates that is solely online, keeping all students engaged is exceedingly difficult, but "Think-Pair-Share" does just that.

With many K-12 schools and higher education institutions opting to go on-line, social-emotional learning stands to be left behind if not addressed by educators. This became clear to me when we first went into quarantine in spring 2020. Educators were scrambling to transition on-line -the content was 
the first to make the transition, but the social-emotional aspect lagged. However, from my experience with Think-Pair-Share in a virtual setting, educators have an opportunity to facilitate a positive social environment, a community of learners if you will - proving Think-Pair-Share a powerful and expandable tool in both face-to-face and virtual settings. Through this consequential Think-Pair-Share experience, I have grown to understand the value and practicality of this technique, and I plan to use it in my future classroom.

\section{Carolyn G. Snell: Teacher Candidate Perspective}

My initial reaction upon learning that Niagara University would be delivering the graduate education program in an online format for the summer 2020 semester was disappointment. Having completed my undergraduate degree at the University of Western Ontario in 2017, I had been looking forward to returning to a university campus where I could meet new people and continue my education. In addition, as a Canadian student, I was excited to visit the United States and make some new connections abroad. Such an important aspect of teaching and learning is collaboration. As teachers, collaboration with our peers and faculty is essential for reflecting on our past and present teaching practices and future practices that we plan to implement in the classroom. I was worried that my peers and I would miss the traditional on- campus collaboration that comes with being face-to-face with your peers. We have all had to adjust and sacrifice because of Covid-19 to keep everyone safe. Despite having to convert what I believe to be a truly social experience into an online format, the professors at Niagara University have done their best to make our online classes as collaborative and social as possible.

Dr. Vermette and Dr. Bardsley utilized Dr. Frank Lyman's (1981) Think-Pair-Share model in our graduate studies class, which has been the highlight of the class for many of my peers and me. Before the class began, the professors gave us our first assignment, which was an All About Me questionnaire. Based on the survey answers, the professors paired candidates with a study buddy, which allowed easy collaboration when the Think-Pair-Share model was utilized. Since the moment my study buddy and I were put in contact with each other, we had been communicating on a regular basis. Not only did we collaborate during class time, but we talked openly about our lives, our families, and our goals during our free time. Although my study buddy lives in the United States and I live in Canada, we use several free apps to communicate through text messaging, audio calls, and video calls. The discussions between my study buddy and I fostered a greater sense of comradery in the online classroom and allowed me to establish a relationship with my peers. Whether we were asking each other for clarification on an assignment, or offering words of encouragement when we felt stressed, I knew that there was another person that I could confide in.

By communicating with my study buddy about course content and assignments, I had greater direction in the virtual classroom. Although my study buddy and I completed our assignments independently, we would discuss how to approach each assignment and discuss the concepts covered in class in a more in-depth way. If we needed clarification, we would first speak to each other, and then if we required additional guidance, we could then contact Dr. Vermette and Dr. Bardsley. I feel that Think-Pair-Share and pairing students with a study buddy is a great way to build a better sense of community in the virtual classroom, where social interactions may otherwise be limited. I would integrate Think-Pair-Share and use the study buddy approach in my future classroom, virtual or face-toface, as it eliminates cliques and creates a more inclusive environment. In addition, because students can communicate with their study buddy on their own terms, they do not feel judgement or pressure from 
their peers for talking with students outside of their typical social circles. Throughout the six-week course, my study buddy and I established a strong working relationship and friendship. In the future, I would like to be paired with more students in my class so that I could have the opportunity to collaborate with and get to know more of my peers.

Dr. Vermette and Dr. Bardsley are the first professors I have met who encourage students to take out their phones and text or call their classmates to collaborate during virtual class time. In the online classroom, I would engage in private discussions with my study buddy about course content, guest speakers or anything else we felt compelled to share, which made the class more enjoyable and interactive. I think using the Think-Pair-Share model is especially beneficial in the online classroom because it provides a sense of connectedness and community that is often lacking in virtual interactions. Not only does Think-Pair-Share allow students to benefit from collaborating with peers and share ideas, it keeps them engaged and allows them to socialize in a safe way during the pandemic. Therefore, I believe Think-Pair-Share is an essential strategy for continuing collaboration and providing a sense of community in the "new" virtual classroom.

\section{Professor Insights, Observations and Reflections}

We discovered several things about "TPS in a remote setting" as the course progressed. First, in one class we ran out of time and did not use the technique during class. We received unsolicited feedback in almost all student reflections that week. Candidates really "missed" talking privately to their partners as classroom routine. The study buddy became normalized; an anticipated part of their processing of the daily stream of ideas offered during the lengthy class. They largely felt safe, encouraged, appreciated, and refreshed (the break from laborious focus on the screen). They also felt the very advantages that Lyman had expected from the TPS process.

Second, when called upon individually during class, our candidates would join one or both instructors "on screen." Candidates, speaking to all 38 of us on screen, routinely shared their partner's observations or used the plural pronoun "We." Education became something to be shared and collaboration was the norm. This was an output of its use and was derived from the philosophy of professional collaboration, conversational discourse, and, perhaps, by human nature. Humans are social beings and human life prospers when it feels like a shared communal experience.

Third, because of Dr. Bardsley's vision the candidates received an email prior to Class \#1, asking them to contact their partners and be ready to share during Class \#1. These pre-meetings of the paired candidates meant that pairs already had a first experience with "the other" conducted before the first hours of formal class. Thus, when we did: (1) a Venn-structured commonalities task, and then (2) a lengthy paired interview in the first hour, the partners were well established in a safe, productive, interdependent (Johnson and Johnson, 2009) and enjoyable manner. Candidates listened with empathy and understanding, found humor with each other and felt a sense of wonderment and awe, all of which introduced three of the Habits of Mind (Costa \& Kallick, 2014) that were found in the course content.

Fourth, as instructors, after completing the course, we reviewed 216 written reflections ( 6 per candidate $\mathrm{x} 36$ candidates) to cull themes regarding the use of study buddies. Both instructors read each reflection looking for recurring themes regarding the study buddy and TSP strategies. We then compared our notes finding that candidates looked forward to openly sharing insights on controversial issues or comments that arose during our (10) guest speaker sessions or in the readings (drawn from 5 
texts). It was safe for candidates to see alternatives and they expected to have more than one "take" on any assertion. Diversity of ideas and discussion of these ideas became central to the course structure; frequently shared critical thinking became a norm.

Fifth, the partnership approach supported the pre-service teachers' understanding of how to create and support culturally relevant classrooms. The course used a variety of texts as part of its framework including Dreamkeepers (Ladson-Billing, \& Dispositions (Costa \& Kallick, 2013), both of which emphasize a community of learners and the need to work interdependently.

In every class session, pairs discussed their thinking, usually done ahead of time on a take-home project (before making their final submission). The take-home projects included a variety of activities and questions including such things as "What is wrong with a teacher being 'color blind'?" and "How does 'Listening with Empathy and Understanding and Thinking Flexibly' assist both teachers and students?" and "How did the expectations (rules) of Hilliard and Dupree compare?" Moreover, our TPS structure found both commonalities between actual students first and then study buddies safely explored their different experiences, perspectives, and plans. Teacher candidates became part of building and maintaining a community of learners through their experiences in the course.

Sixth, college may be seen as getting past obstacles: the individual work of writing papers, taking tests, doing presentations. We think that the best $\mathrm{K}-12$ teaching and college teaching is different in that it is about thinking and sharing (decision-making), persuading others; appreciating backgrounds and experiences; reacting to and managing unexpected events or comments; and finally, having workshoplike experiences. We think that our class reinforced the idea of "coming to work and expecting to contribute to work," instead of "coming to class, expecting to listen and be unnecessary." We are fearful that remote instruction typically fails to entice a "collaborative learning" perspective that our graduates will need when they get their own classrooms.

One other result that is worth sharing as a hypothesis, though it needs to be more systematically and fully explored, is that the study buddy strategy-built familiarity, trust and a community of learners. After two class sessions we began to shift the prompts to the partners from clear and precise tasks, like "Find two things that you agree with" or "What did the guest speaker say was the reason she got the job?" to far more open-ended, intentionally vague items such as "What were the best parts of the reading?" and "What can you use from the reading?" The latter type of questions entices (or demands) student clarification and interpretation. To us, that meant that their pair had to collaborate and then "own" the question as well as their responses. This intentional use of vagueness (open-endedness) theoretically allows student-directed and student desired conversation and promotes the professional development of aspiring teachers. The passive nature of much on-line instruction needs to change, and we would be wise to use and examine research supported face-to-face techniques, as we did with TPS.

\section{Ending Remarks and Observations by Dr. Frank Lyman}

Think-Pair-Share was invented in a moment of frustration. A classroom teacher, Arlene Mindus, and I were watching a student teacher having serious trouble with a group discussion. The recitation model one-response-at-a-time Jeopardy style discussion, allowing learning space for only a few candidates, was and is an unfair disaster everywhere. We were both tired of being party to the problem and came up with a solution-cue structured Think-Pair-Share. Whereas pair learning was widely used, the idea of building in a cued Wait Time to enable prepared minds before pairing or total class sharing was new on the scene. Combining the thoroughly researched Wait Time mode with pair talk was the missing piece. 
The epiphany of that moment between two frustrated educators has influenced education worldwide. Upon reading the testimony of Philip J. Sembert II and Carolyn Snell, my interest was aroused in cooperative learning and specifically Think-Pair-Share as a crucial ingredient of the virtual classroom. The learning and social benefits of content related pair talk seem especially necessary in the current reality. The additional state of the art elements of the course as described above are rendered more effective through pair interaction. If it is true that we learn that to which we respond, the graduate teachers will remember the meaningful response as well as the methods in this class. In this course, as designed, the medium is surely the message, and I would bet that every graduate student will view the classroom dynamic in a more inclusive way and teach accordingly. As a teacher educator of 26 years' experience, it gives me hope to know that in an online classroom a co-constructivist and cooperative classroom is possible. I see implications for all levels of education.

\section{Conclusion}

This article demonstrates an attempt by two professors at infusing Think-Pair-Share into their course by pairing graduate students as study buddies. Two graduate students provide their perspective of this teaching strategy and Dr. Frank Lyman, developer of TPS, offers insights about this attempt. To add to the wealth of knowledge regarding best practices, the strategy needs to be researched and framed within the fields' literature. We believe there is purpose in providing this information to readers of this journal. Perhaps this article will inspire others to try the study buddy and TPS in virtual environments.

\section{Declaration of Conflicting Interests}

The author declared no potential conflicts of interest with respect to the research, authorship, and/or publication of this article.

\section{Funding}

The authors received no financial support for this research.

\section{References}

Barkley, E., Cross, K., \& Major, C. (2014). Collaborative learning techniques: A handbook for college faculty. John Wiley \& Sons.

Cortright, R., Collins, H., \& DiCarlo, S. (2005). Peer instruction enhanced meaningful learning: Ability to Solve Novel Problems. Advances in Physiology Education, 29(2), 107-11. https://doi.org/10.1152/advan.00060.2004

Costa, A. L., and Kallick, B. (2014). Dispositions: Reframing teaching and learning. Corwin.

Crouch, C., \& Mazur, E. (2001). Peer instruction: Ten years of experience and results. American Journal of Physics, 69(9), 970-977. https://doi.org/10.1119/1.1374249

Gonzales, C., Vermette, P. J., Bardsley, M., \& Alexander, K. (2021). Informing instruction with vignette analysis. Routledge.

Johnson, D. \& Johnson, R. (1989). Cooperation and competition: Theory and research. Interaction Book Company. 
Johnson, D., \& Johnson, R. (2009). An educational psychology success story: Social interdependence theory and cooperative learning. Educational Researcher, 38(5), 365-379. https://doi.org/10.3102/0013189X09339057

Ladson-Billings, G. (2009). The dream keepers: Successful teachers of African American children. Jossey-Bass.

Larson, C., \& Dansereau, D. (1986). Cooperative learning in dyads. Journal of Reading, 29 (6), pp. 516-520. https://www.jstor.org/stable/40032752

Lavin, R. (1983). Cooperative learning: Theory, research \& practice. Allyn \& Bacon.

Lyman, F. (1981). The responsive classroom discussion: The inclusion of all students. In A. Anderson (Ed.), Mainstreaming digest (pp. 109-113). University of Maryland College of Education.

Millis, B. (1990). Helping faculty build learning communities through cooperative groups. To Improve the Academy, 9, 43-58. http://doi.org/10.3998/tia.17063888.0009.007

Nik Azlina, N. (2010). CETLs: Supporting collaborative activities among students and teachers through the use of Think-Pair-Share technique. International Journal of Computer Science Issues, Vol. 7(5), 18-29.

Simon, C. (n.d.) Using the Think-Pair-Share technique. Read Write Think. http://www.readwritethink.org/professional-development/strategy-guides/using-think-pairshare-30626.html

Sugiarto, D. \& Sumarsano, P. (2014). The implementation of Think-Pair-Share model to improve students' ability in reading narrative texts. International Journal of English and Education, 3(3), 206-215.

Vermette, P. (1997). Making cooperative learning work: Student teams in K-12 Classrooms. Pearson.

Vermette, P. and Kline, C. (2017). Groupwork that works: Student collaboration for $21^{\text {st }}$ century success. Routledge, Taylor and Francis. https://doi.org/10.4324/9781315618364 